\title{
Supplementation of antioxidants for in Vitro embryo production of buffaloes
}

\author{
S. S. Ibrahim, A. Aboul-Ela * , E.A. Mabrouk, K.M. Ali, A. A. Ahmed \\ Department of Physiology, Faculty of Veterinary Medicine, Beni-Suef University, Beni-Suef 62511, \\ Egypt
}

\begin{abstract}
Biological hazards associated with oxidative stress resulted in defective in vitro embryo production "IVEP". Reactive oxygen species "ROS" may originate from embryo metabolism and/or embryo surroundings. In an attempt to overcome such challenge, the present study correlates between the influence of 3 antioxidants and buffalo oocyte development up to morula and blastocyst stages. It was found that taurine addition (either alone or concomitant with ascorbic acid "AA" or mannitol) to media during in vitro maturation "IVM" has the potency to enhance IVEP in buffaloes. On the other side, AA and mannitol either alone or in combination are invalid to improve developmental rate of mature buffalo oocytes to reach morula and blastocyst stages.

In a second experiment, the best treatment (taurine and AA) was added to both in vitro fertilization "IVF" and culture "IVC" media. This treatment resulted in significant elevation of the cleavage rate and morula development without influencing blastocyst rate as compared with their corresponding values following the addition to IVM medium alone. Thus, it could be concluded that addition of taurine with AA into both IVM and IVF media enhances maturation of buffalo oocytes and activates the cells to undergo cleavage and morula development.
\end{abstract}

Among livestock, water buffalo is a principal source of milk, meat and ideal for fattening. However, the reproductive activity of such animal suffers from a series of disturbances leading to subfunctional ovarian performance and elongation of calving interval. Moreover, ovulations are highly unpredictable, thus frustrating breeding management.

Various methods have been sought to overcome infertility among buffaloes; IVF and embryo transfer have become indispensable. In this concern, efforts have been directed to use various additives to the maturation medium to improve the yield of IVF (Fukui, 1989 in cattle and Gasparrini, 2002 and Atef, 2005 in buffaloes). Moreover, studies have been implemented to apply various antioxidants to the maturation medium (Ealy et al., 1995 and Fujitani et al., 1997). In this respect, it was documented that oxygen concentration within the reproductive tract of

\footnotetext{
* Corresponding author. Tel.: +20 0822322066; fax: +20822327982 .

E-mail address: ahmedmohamed744@hotmail.com (Ahmed Aboul-Ela).
}

mammals is lower than that in air (Kessler, 1974). Furthermore, the cleaving embryos has an optimal oxygen requirement in vitro approximately equivalent to $5 \%$ and blastocysts that developed under $20 \% \mathrm{O}_{2}$ had fewer cells than those developed under $5 \%$ (Quinn and Harlow, 1978 and Fujitani et al., 1997). Manipulation of oocytes and embryos in an in vitro environment carries the risk of cell exposure to higher levels of ROS. This condition of increased ROS levels without concomitant rise in antioxidant defense leads to oxidative stress upon developing embryos resulting in lipid, protein and even DNA damage responsible consequently for defective embryo development (Fujitani et al., 1997; Sikka, 2004 and Agarwal et al., 2006).

Therefore, the current study is an endeavor to clarify the influence of a variety of antioxidants (mannitol, taurine and AA) added to hormone enriched media on IVEP in buffalo cows.

\section{Materials and methods}

This study was done during October 2007March 2008. All chemicals and media were purchased from Sigma Chemical Co., St. Louis, MO, USA unless otherwise indicated. Media and 
buffers were freshly prepared and sterilized by passing them through $0.22 \mu \mathrm{m}$ millipore membrane filter while the mineral oil was sterilized by $0.45 \mu \mathrm{m}$ diameter filter (Sterivex-GV, Bedford, MA, USA). The solutions were allowed to equilibrate for $1 \mathrm{hr}$. in $\mathrm{CO}_{2}$ incubator before being applied to the oocytes (Leibfried and First, 1979). Presterilized disposable plastic tools were used once.

Cyclic buffalo ovaries $(\mathrm{n}=1658)$ were collected from El-Hawamdya abattoir and preserved in a thermos containing presterilized warm $\left(25^{\circ} \mathrm{C}\right)$ saline (Gordon, 1994) supplemented with $100 \mu \mathrm{g} / \mathrm{ml}$ streptomycin sulfate and 100 i.u. penicillin G (Pavasuthipaisit et al., 1992) then transported within 2 hours (Leibfried-Rutledge et $a l ., 1987)$ to the laboratory where they were washed thrice with presterilized warm saline. Retrieval of immature primary oocytes (cumulus oocytes complexes "COCs") was carried out using the aspiration method (Suzuki et al., 1992). The collected COCs were washed thrice in PBS containing $10 \mathrm{mg} / \mathrm{ml} \mathrm{BSA}$ and also thrice with Ham's F-10 medium supplemented with $50 \mu \mathrm{g} / \mathrm{ml}$ gentamycin sulfate and $5 \mu \mathrm{l} / \mathrm{ml} \mathrm{L}$-glutamine. The cells were examined under microscope and classified into 3 categories : oocytes with evenly granulated cytoplasm and completely surrounded by multiple layers of cumulus cells (grade I), oocytes surrounded by scanty layers of cumulus cells (grade II ) and nude oocytes (grade III) which were excluded from the study. In vitro maturation of oocytes was done in digitally adjustable $\mathrm{CO}_{2}$ incubator favors $5.0 \% \mathrm{CO}_{2}, 39^{\circ} \mathrm{C}$ and $95 \%$ relative humidity and Ham's F-10 medium with $10 \%$ fetal calf serum "FCS ", 50 $\mu \mathrm{g} / \mathrm{ml}$ gentamycin sulfate and $5 \mu \mathrm{l} / \mathrm{ml} \mathrm{L}$-glutamine was used for maturation (Totey et al., 1993). The oocytes were subjected to 2 separate experiments; in the first the oocytes were exposed to the following treatments:

Group I (Control).The maturation medium was devoid of antioxidants but contained 0.2 i.u FSH (Gonal-F, Laboratoires Serono S.A., Switzerland), 2.0 i.u. hCG (Pregnyl, Nile Co. for Pharm., Cairo, Egypt) and $1.0 \mu \mathrm{g} \mathrm{E}_{2} / \mathrm{ml}$ medium (Atef, 2005). This control medium was used as a basal maturation medium (BMM) applied in the following groups.

Group II (BMM with 0.3M mannitol). (Okada et al., 2006).
Group III. BMM was supplemented with $10 \mathrm{mM}$ taurine (Takahashi and Kanagawa, 1998).

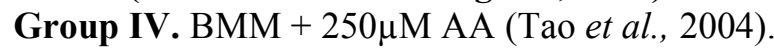
Group V. 0.3M mannitol $+10 \mathrm{mM}$ taurine were added to BMM.

Group VI. The BMM contained 0.3M mannitol + $250 \mu$ M AA.

Group VII. BMM with $10 \mathrm{mM}$ taurine $+250 \mu \mathrm{M}$ AA.

Each treatment included a number of grade I and II oocytes contained in droplets of the maturation medium each of $50 \quad \mu l \quad(10$ COCs/droplet).

In Experiment II, a treatment included a mixture of taurine and AA was applied to oocyte media during IVF and IVC as from Experiment I, this combination gave the best results.

The oocytes were incubated for maturation in $\mathrm{CO}_{2}$ incubator for $24 \mathrm{hrs}$. (Fukui, 1990) then examined under stereomicroscope for evaluation of cumulus mass expansion. Accordingly, the cells were classified into 3 classes : excellent, good and unexpanded (Schellander et al., 1989). In vitro capacitation of buffalo spermatozoa (frozen buffalo semen received from Artificial Insemination Centre, Beni Suef) was adopted according to Parrish et al., (1988). IVF and culturing was done as described by Atef (2005). The presence of cleaved cells (2-16) as well as morula and blastocyst stages was recorded and the number of embryos which cleaved at least once was calculated. Data were subjected to statistical analysis as outlined by SAS Program (1994).

\section{Results}

Table 1 displays that oocyte recovery rate reached $1.11 \pm 0.03 \%$. Grade I and grade II represented $33.73 \pm 0.54$ and $39.33 \pm 0.72 \%$, respectively while nude oocytes \% reached 27.34 \pm 0.61 ; a value which differs significantly ( $\mathrm{P}$ $\leq 0.001)$ than the corresponding grade I and II oocytes. In addition, the recovery rate of grade I and II oocytes, undergoing subsequent maturation, was 0.72 /ovary.

It appears from table 2 that the best maturation rate $\%$ was after a combination between taurine and AA followed by taurine alone then addition of taurine to mannitol. Also, addition of AA alone increased significantly the maturation rate while addition of either mannitol alone or in combination with AA did not induce any significant improvement compared with the corresponding 
control values. Cleavage rate, as indicated by number of oocytes underwent cleavage (up to 16 cells) / total number of excellent and good mature oocytes, showed that the ideal treatment was the combination between taurine and AA followed by either taurine alone or with mannitol while AA treatment and either mannitol alone or concomitant with AA did not enhance cleavage rate than that of the control group.

Table 3 disclosed that the best treatment induced highest morula development was the mixture between taurine and AA followed by either taurine alone or accompanied with mannitol while AA and either mannitol alone or concomitant with AA did not stimulate morula development as compared with the corresponding control. In addition, combination between taurine and $\mathrm{AA}$ induced the highest rate for transformation of morulae into blastocysts followed by either taurine alone or accompanied with mannitol as compared with control value. On the contrary, treatments including AA and either mannitol alone or accompanied with AA did not give better blastocyst developmental rate than that of the control.

In experiment II (Table 4), addition of taurine and AA mixture to IVM and IVF media resulted in significant elevation of the cleavage rate and morula development compared with their corresponding values following addition of this treatment to IVM medium alone without influencing blastocyst developmental rate. This improvement was not further increased when the antioxidants were added into the IVC medium.

Table 1 : Classification of the recovered buffalo oocytes (Mean $\pm \mathrm{SE}$ ).

\begin{tabular}{|c|c|c|c|c|c|}
\hline \multirow{2}{*}{$\begin{array}{l}\text { Number } \\
\text { of ovaries }\end{array}$} & \multirow{2}{*}{$\begin{array}{c}\text { Number of } \\
\text { recovered } \\
\text { oocytes }\end{array}$} & \multirow{2}{*}{$\begin{array}{c}\text { Recovery rate } \\
(\%)\end{array}$} & \multicolumn{3}{|c|}{ Qualitative classification of buffalo oocytes (\%) } \\
\hline & & & Grade I & Grade II & Grade III \\
\hline 1658 & 1842 & $1.11 \pm 0.03$ & $33.73 \pm 0.54^{*}$ & $39.33 \pm 0.72^{*}$ & $27.34 \pm 0.61^{*}$ \\
\hline
\end{tabular}

SE : Standard error.

In the same row, values having * superscript differ significantly from each others at $\mathbf{P}<0.001$.

Table 2 : Maturation and cleavage rates $\%$ of buffalo oocytes following addition of different antioxidants (Mean \pm SE).

\begin{tabular}{lccc}
\hline Treatment & No. of oocytes & Maturation rate \% & Cleavage rate \% \\
\hline Control & 207 & $84.54 \pm 0.34^{\mathrm{ADG}}$ & $50.45 \pm 0.75^{\mathrm{ABC}}$ \\
Mannitol & 211 & $84.42 \pm 0.79^{\mathrm{BE}}$ & $50.50 \pm 0.51^{\mathrm{DK}}$ \\
Taurine & $212^{\mathrm{ABC}}$ & $55.17 \pm 0.59^{\mathrm{ADEF}}$ \\
Ascorbic acid (AA) & 205 & $90.28 \pm 0.92^{\mathrm{ABC}}$ & $48.70 \pm 1.67^{\mathrm{EGH}}$ \\
Mannitol + Taurine & 209 & $86.73 \pm 0.13^{\mathrm{ABE}}$ & \\
Mannito + AA & $212^{\mathrm{BFG}}$ & $55.80 \pm 0.32^{\mathrm{BGIK}}$ \\
Taurine + AA & 214 & $85.97 \pm 0.48^{\mathrm{CF}}$ & $50.65 \pm 1.18^{\mathrm{FIJ}}$ \\
\hline
\end{tabular}

In the same column, values sharing one similar letter differ significantly from each others (at least $\mathbf{P} \leq \mathbf{0 . 0 5}$ ). 
Table 3 : Rate of morula development / cleaved oocytes and blastocyst development / morulae following addition of different antioxidants to maturation medium ( Mean $\pm \mathrm{SE}$ ).

\begin{tabular}{lcccc}
\hline Treatment & $\mathbf{N}_{\mathbf{1}}$ & $\begin{array}{c}\text { Morula } \\
\text { Development ( \% ) }\end{array}$ & $\mathbf{N}_{\mathbf{2}}$ & $\begin{array}{c}\text { Blastocyst } \\
\text { Development ( \% ) }\end{array}$ \\
\hline Control & 44 & $43.78 \pm 0.56^{\mathrm{AB}}$ & 20 & $38.30 \pm 1.46^{\mathrm{ABC}}$ \\
Mannitol & 46 & $43.72 \pm 0.46^{\mathrm{CD}}$ & 20 & $37.86 \pm 1.55^{\mathrm{DEF}}$ \\
Taurine & 50 & $47.68 \pm 0.42^{\mathrm{ACE}}$ & 23 & $41.80 \pm 1.01^{\mathrm{ADGH}}$ \\
Ascorbic acid (AA) & 41 & $42.90 \pm 1.13^{\mathrm{EF}}$ & 18 & $38.41 \pm 1.07^{\mathrm{GIJ}}$ \\
Mannitol + Taurine & 45 & $47.97 \pm 0.61^{\mathrm{BDF}}$ & 22 & $42.06 \pm 1.17^{\mathrm{BEIK}}$ \\
Mannitol + AA & 44 & $45.33 \pm 1.71^{\mathrm{G}}$ & 20 & $36.05 \pm 2.07^{\mathrm{HKL}}$ \\
Taurine + AA & 43 & $52.14 \pm 0.60^{\mathrm{ADFG}}$ & 23 & $43.03 \pm 1.56^{\mathrm{CFJL}}$ \\
\hline
\end{tabular}

SE : Standard error.

$\mathrm{N}_{1}$ : No. of cleaved oocytes. $\quad \mathrm{N}_{2}$ : No. of morulae.

In the same column, values sharing one similar letter differ significantly from each others (at least $P \leq 0.05$ ).

Table 4 : Cleavage rate as well as morula and blastocyst development \% of buffalo embryos following addition of taurine and ascorbic acid to both IVF and IVC media ( Mean \pm SE ).

\begin{tabular}{cccc}
\hline Type of media & Cleavage rate \% & Morula \% & Blastocyst \% \\
\hline IVM & $56.95 \pm 0.72^{\mathrm{AB}}$ & $52.14 \pm 0.60^{\mathrm{AB}}$ & $43.03 \pm 1.56$ \\
IVF & $64.85 \pm 1.74^{\mathrm{A}}$ & $57.92 \pm 2.11^{\mathrm{A}}$ & $45.25 \pm 3.21$ \\
IVC & $62.76 \pm 2.07^{\mathrm{B}}$ & $56.09 \pm 2.03^{\mathrm{B}}$ & $44.19 \pm 2.97$ \\
\hline
\end{tabular}

SE : Standard error.

In the same column, values sharing one similar letter differ significantly from each others (at least $P \leq 0.05)$.

\section{Discussion}

In the present study, ovaries of apparently healthy cyclic buffaloes were collected from abattoir in order to retrieve oocytes. This method is considered an easy, available and inexpensive to obtain oocytes as well as it provides a source to collect a large number of cells during the shortest period (Abd Allah, 2003 and Atef, 2005). In addition, the ovaries yield a higher distribution percentage of primary follicles than the decreased value detected in the pregnant buffaloes (Goswami, 1985). Moreover, Abd Allah (2003) recorded in buffalo that cyclic ovaries gave a higher number of oocytes/ ovary than that obtained from animals with ovarian defects. The collected buffalo ovaries were transferred to the laboratory preserved in presterilized warm $\left(35^{\circ} \mathrm{C}\right)$ saline within 2 hours. This time interval is critical for successful IVEP as an inverse relation was recorded between storage time and percentages of cleavage and blastocyst formation (Lonergan et al., 1992). Moreover, Pollard et al., (1996) in cows reported that the blastocyst formation was $33.70 \%$ higher among oocytes recovered from ovaries preserved at $35^{\circ} \mathrm{C}$ than those at either 25 or $30^{\circ} \mathrm{C}$; a result that contradicts the study of Yang et al., (1990) who recorded that cleavage and blastocyst rates were higher when ovaries were preserved at $24^{\circ} \mathrm{C}$ than those at $37^{\circ} \mathrm{C}$.

Many techniques were outlined for oocyte recovery including ovarian dissection, slicing and aspiration of vesicular follicles. The current study used the aspiration one. Leibfried and First (1979) recommended this way because of its advantage in speed of collection which is important for commercial IVEP. Also, Datta and Goswami (1998) in buffaloes recorded lower oocytes recovery by slicing method than that after aspiration; a finding that motivated Abd Allah (2003) and Atef (2005) in buffaloes to use aspiration procedure.

From table 1, the recovery rate was $1.11 \pm 0.03$ $\%$. Grade I and II oocytes was $33.73 \pm 0.54$ and $39.33 \pm 0.72 \%$, respectively with $27.34 \pm 0.61$ nude 
cells. In buffaloes, variable rates were previously reported (Suzuki et al., 1992; Hammam et al., 1997 and Atef, 2005). This variation is due to age, follicle size, ovarian status, genetic factor and health condition (Ahmed et al., 1999; Hagemann, 1999 and Abd-Allah, 2003). Also, oocytes convenient to undergo maturation was 0.73 which is $>0.20$ (Jain et al., 1995) and $<1.77$ (Abd Allah, 2003).

The BMM used for IVM of buffalo oocytes was Ham's F-10 medium enriched with hormones (Atef, 2005). Totey et al., (1993) and Abass (1998) found that Ham's F-10 medium supplemented with FCS and hormones was most suitable for buffaloes. Furthermore, Badr (2001) observed excellent cumulus expansion with high in vitro nuclear maturation, sperm penetration, cleavage rate and embryo development when buffalo oocytes were cultured in Ham's F-10 and TCM199. Hormonal addition during IVM improved maturation and subsequent embryonic development (Atef, 2005). These findings coincide with the results of Younis et al., (1989) and Nakagawa and Leibo (1997) who revealed that addition of even a single hormone (LH) or in combination with $\mathrm{FSH}$ and $\mathrm{E}_{2}$ significantly enhanced the rate of bovine oocytes maturation. FSH and LH receptors are present on cumulus cell (Gasparrini, 2002) thus they elicit their effect via cumulus mediated interactions. Estradiol addition to IVM medium improved the completion of maturation, including the synthesis of the male pronucleus growth factor in the nucleus and cytoplasm of mammalian oocytes (Fukui et al., 1982).

Regarding addition of antioxidants to IVM medium, it appears from table 2 that the best maturation rate was after application of a combination between taurine and AA followed by taurine. Also, addition of AA alone increased significantly the maturation rate while mannitol alone or in combination with AA did not induce any significant improvement. These findings coincide with previous studies that revealed the importance of taurine supplementation to enhance in vitro development of rabbit (Li et al., 1993), pig (Reed et al., 1992) and cattle embryos (Liu et al., 1995). Furthermore, Ali et al., (2003) recorded that addition of taurine or its derivatives improved bovine embryo development in contrast to extracellular antioxidants like catalase and superoxide dimutase "SOD" that caused no improvement. Gardner and Lane (1997) emphasized that taurine also serves as an osmolyte that buffers the intracellular $\mathrm{pH}$ of maturing oocytes. Regarding AA, Olson and Seidel (2000) and Tatemoto et al., (2001) reported that AA reduced the threat of cellular apoptosis, enhanced synergistically the antioxidant effect of vitamin $\mathrm{E}$ and supported the cytoplasmic maturation during IVEP. Also, Tao et al., (2004) found that AA prevented cumulus cell DNA fragmentation.

Table 2 also showed that combination between taurine and AA was optimal to enhance cleavage rate followed by either taurine alone or accompanied with mannitol as compared with the corresponding control value while AA and either mannitol alone or concomitant with AA did not enhance cleavage rate. These findings emphasize the role of taurine to stimulate IVF and cleavage in buffaloes. Dumoulin et al., (1992) and Gardner and Lane (1997) clarified that taurine had a beneficial regulating effect on phospholipids and membrane protein receptor interactions as well as protects newly - formed embryo from impairment due to high potassium concentrations. Furthermore, Tatemoto et al., (2001) recorded that AA enhanced transformation of the sperm nucleus into the male pronucleus (MPN) after IVF. However, in the present study AA alone or combined with mannitol did not show potential influence upon IVF; a finding which comes in agreement with that reported by Dalvit et al., ( 2005 ) in bovine.

Data presented in table 3 clarify that combination between taurine and AA in maturation medium is the option to induce highest morula and blastocyst development followed by either taurine alone or accompanied with mannitol as compared with the corresponding control values. On the other side, AA and either mannitol alone or concomitant with AA did not show any effect to enhance the development. Supplementation of maturation media with taurine has been demonstrated to enhance in vitro development of embyos (Li et al., 1993 and Liu et al., 1995). In addition, Fujitani et al., (1997) and Takahashi and Kanagawa (1998) detected that taurine improved the development of 4-8 cell bovine embryos to the blastocyst stage after 6 days of culture. Ali et al., (2003) observed significant improvement in the proportion of oocytes undergoing morula and blastocyst development 
when taurine was added to the maturation medium compared with the medium devoid of antioxidants.

Therefore, it could be concluded that taurine addition (either alone or concomitant with AA or mannitol) to media during IVM has the potency to enhance IVEP in buffaloes. On the other side, AA and mannitol either alone or in combination are invalid to improve developmental rate of mature buffalo oocytes to reach morula and blastocyst stages.

In the second experiment, the best treatment (taurine and AA) was added to both IVF and IVC media. Table 4 reveals that addition of this treatment resulted in significant elevation of the cleavage rate and morula development without influencing blastocyst developmental rate as compared with their corresponding values following addition of this treatment to IVM medium alone. Thus, it could be concluded that addition of taurine and AA into both IVM and IVF media is the best formula to achieve beneficial enhancement for maturation of buffalo oocytes as well as their activity to undergo cleavage and morula development while supplementation of IVC medium does not lead to further increment in these rates. In addition, it seems that the combination between taurine and AA has the potential activity for reducing the oxidative stress during IVM and IVF which favors better environment for the developing embryo to undergo further development up to morula and blastocyst stages. From the present study, it is worth mentioning that the application of the proposed combination between the aforementioned antioxidants during IVM-IVF is not cited in the literature for IVEP in cattle and buffalo (Fujitani et al., 1997; Takahashi and Kanagawa, 1998; Ali et al., 2003 and Dalvit et al., 2005 ); a finding that opens the gates for better mechanisms that allow inhibition of ROS during IVEP in buffaloes.

\section{References}

Abass, H. S. (1998): Investigations on in - vitro fertilization in buffaloes. Ph.D. Thesis, Fac. Vet. Med., Zagazig Univ.

Abd Allah, S. M. (2003): In vitro fertilization, processing and cryopreservation of buffalo oocytes and embryos. Ph.D.Thesis (Theriogenol.), Fac. Vet. Med., Beni - Suef Univ.

Agarwal, A.; Said, T. M.; Bedaiwy, M. A.; Banerjee, J. and Alvarez, J. (2006): Oxidative stress in an assisted reproductive techniques setting. Fert. Steril., 86:503-512.

Ahmed, W. M.; Abdoon, A. S.; Shalaby, S. I. and Kandil, M. T. (1999): Effect of reproductive status and body condition on ovarian follicles and oocytes quality in buffalo cows. Buffalo. J., $3: 333-343$.
Ali, A. A.; Bilodeau, J. F. and Sirard, M. A. (2003): Antioxidant requirements for bovine oocytes varies during in vitro maturation, fertilization and development. Theriogenol., 59 ( 3-4 ): 939-949.

Allen, R. L.; Bondiole, K. R. and Wright, R. W. (1982): The ability of FCS, new born calf serum and normal steer serum to promote the in vitro development of bovine morulae. Theriogenol., $18: 185-189$.

Atef, N. (2005): Some studies on in vitro fertilization in buffaloes. MVSc Thesis (Physiology), Beni Suef Univ.

Badr, M. R. (2001): In vitro maturation, fertilization and development of buffalo oocytes. Ph.D. Thesis, Fac. Vet. Med., Zagazig Univ., Benha branch.

Dalvit, G.; Llanes, S. ; Descalzo, A.; Insani, M.; Beconi, M. et al. (2005): Effect of alpha-tocopherol and ascorbic acid on bovine oocyte in vitro maturation. Reprod. Domest. Anim., 40 (2): 93-97.

Datta, T.K. and Goswami, S. L. (1998): Feasibility of harvesting oocytes from buffalo (Bubalis bubalis) ovaries by different methods. Buffalo J., 2:277-284.

Dumoulin, J.; Evers, J. L. H.; Bras, M.; Hansen, P. J.; Moor, R. M. et al. (1992): Positive effect of taurine on preimplantation development of mouse embryos in vitro. J. Reprod. Fertil., 94: 373-380.

Ealy, A. D.; Howell, J. L.; Monterroso, V. H.; Arechiga, C. F. and Hansen, P. J. (1995): Developmental changes in sensitivity of bovine embryos to heat shock and use of antioxidants as thermoprotectants. J. Anim. Sci., 73:14011407.

Fujitani, Y.; Kasai, K.; Ohtani, S.; Nishimura, K.; Yamada, M. et al. (1997): Effect of oxygen concentration and free radicals on in vitro development of in vitro produced bovine embryos. J. Anim. Sci., 75 : 483-489.

Fukui, Y. (1989): Effects of sera and steroid hormones on development of bovine oocytes matured and fertilized in vitro and co - cultured with bovine oviduct epithelial cells. J. Anim. Sci., $67: 1318$-1323.

Fukui, Y. (1990): Effect of follicle cells on acrosome reaction, fertilization and development competence of bovine oocytes matured in vitro. Mol. Reprod. Dev., 26: 40-46.

Fukui, Y.; Fukushima, M.; Terawaki, Y. and Ono, H. (1982) : Effect of gonadotropins, steroids and culture medium on bovine oocyte maturation in vitro. Theriogenol., 18:161175.

Gardner, D.K. and Lane, M. (1997): Culture and selection of viable blastocysts: a feasible proposition for human IVF?. Hum. Reprod. Update, 3: 367-382.

Gasparrini, B. (2002): In vitro embryo production in buffalo species : state of the art. Theriogenol., 57: 237 - 256.

Gordon, I. (1994) : Laboratory Production of Cattle Embryos. CAB Intern., Wallingford, UK Univ. Press, UK.

Goswami, R. K. (1985): Histomorphological and histochemical observations on ovary in murrah buffaloes. MVSc Thesis, Haryana Agric. Univ., Hisar, India.

Hagemann, L. J. (1999): Influence of the dominant follicle on oocytes from subordinate follicles. Theriogenol., 51:449459.

Hammam, A. M.; Zabaal, M.M. and Sabra, H. A. (1997): Effect of types of media on in vitro maturation, culture and fertilization of buffalo and cattle oocytes. Beni-Suef Vet. Med. Res., 5 : 242-258. 
Jain, G.C.; Das, G.K.; Solanki, V.S. and Tripathi, V.N. (1995): Comparative efficiency of different collection technique for oocyte retrieval in buffalo. Theriogenol., 43 : 240-249.

Kessler, M. (1974): Oxygen supply to tissue in normoxia and in in oxygen deficiency. Microvasc. Res., $8: 283-287$.

Leibfried, L. and First, N. L. (1979): Charachterization of bovine follicular oocytes and their ability to mature in vitro. $\mathrm{J}$. Anim. Sci., $48: 76$ - 86.

Leibfried - Rutledge, M.L.; Crister, E.S.; Eyestone, W.H.; Northey, D.L. and First, N.L. (1987) : Developmental potential of bovine oocytes matured in vivo and in vitro. Biol. Reprod., $36: 376$ - 383.

Li, J.; Foote, R. H. and Simkin, M. (1993): Development of rabbit zygotes cultured in protein - free medium with catalase, taurine or superoxide dimutase. Biol. Reprod., $48: 33$ - 37.

Liu, Z.; Foote, R. H. and Yang, X. (1995): Development of early bovine embryos in co - culture with KSOM and taurine, superoxide dimutase or insulin. Theriogenol., 44 : $741-750$.

Lonergan, P.; Fair, T. and Gordon, I. (1992): Effect of time of transfer to

Granulose cell monolayer and cell stage at 48 hours postinsemination on

bovine oocyte development following IVM / IVF / IVC. Proc. $8^{\text {th }}$ Conf. Europian Embryo Transfer Assoc. ( Lyon ):178-185.

Naka-gawa, A. and Leibo, S. P. (1997): Influence of lutienizing hormone on nuclear maturation of bovine oocytes in vitro. Theriogenol., 48: 198-205.

Okada, K.; Krylov, V.; Kren, R. and Fulka, J. (2006): Development of pig embryos after electro-activation and in vitro fertilization in PZM-3 or PZM supplemented with fetal bovine serum. J. Rep. Dev., 52: 914 -918.

Olson, S. E. and Seidel, G. E. (2000): Culture of in vitroproduced bovine embryos with vitamine $\mathrm{E}$ improves development in vitro and after transfer to recipients. Biol. Reprod., 62 : 248-252.

Parrish, J. J.; Susko - Parrish, J. L.; Winer, M. A. and First, N. L. (1988): Capacitation of bovine sperm by heparin. Biol. Reprod., 38:1171-1180.

Pavasuthipaisit, K.; Kitiyanant, M.; Thonabulsombat, C.; Tocharus, C.; Sriurairatna, S. et al. (1992): In vitro maturation and fertilization of swamp buffalo oocytes and their subsequent development. Theriogenol., 38: 545-555.

Pollard, J.W.; Martino, A.; Rumph, N.D.; Songsaaen, N.; Plante, C. et al. (1996): Effect of ambient temperature during oocyte recovery on IVP of bovine embryos. Theriogenol., 46: 849-859.

Quinn, P. and Harlow, G.M. (1978): The effect of oxygen on the development of preimplantation mouse embryos in vitro. J. Exp. Zool., 206: 73-79.

Reed, M. L.; Illera, M. J. and Petters, R. M. (1992): In vitro culture of pig embryos. Theriogenol., 37: 95-109.

SAS Program (1994): SAS User Guide Statistics. SAS Inst. Carry, NC., USA.

Schellander, K.; Fayer-Hosken, R. A.; Keefer, C. L.; Brown, L. M. and Malter, H. (1989): In vitro fertilization and cleavage of bovine follicular oocytes recovered by laparoscopy. Theriogenol., 31 : 927-934.

Sikka, S. C. (2004): Role of oxidative stress and antioxidants in andrology and assisted reproductive technology. J. Androl., 25: 5-18.

Suzuki, T.; Singla, S.K.; Sujata, J. and Madan, M.L. (1992): In vitro fertilization of water buffalo follicular oocytes and their ability to cleave in vitro. Theriogenol., 38: 11871194.

Takahashi, Y. and Kanagawa, H. (1998): Effects of glutamine, glycine and taurine on the development of in vitro fertilized bovine zygotes in a chemically defined medium. J. Anim. Reprod. Sci., 60 ( 4 ): 433-437.

Tao, Y.; Zhou, B.; Xia, G. and Fu, M. (2004): Effect of Lascorbic acid or $\alpha$ - Tochopherol affects the development of porcine denuded oocytes from metaphase I to metaphase II and prevents cumulus cells from fragmentation. Reprod. Domest. Anim., 39: 52-57.

Tatemoto, H.; Ootaki, K.; Shigeta, K. and Muto, N. (2001): Enhancement of developmental competence after in vitro fertilization of porcine oocytes by treatment with ascorbic acid 2-O-alpha-glucoside during in vitro maturation. Biol. Reprod., 65 ( 6 ): 1800-1806.

Totey, S.M.; Pawshe, C.H. and Singh, G. (1993): Effects of bull and heparin and sperm concentration on IVF of buffalo (Bubalus bubalis) oocytes matured in vitro. Theriogenol., 39: 887-898.

Yang, N. S.; Lu, K.H. and Gordon, I. (1990): In vitro fertilization and culture of bovine oocytes from stored ovaries. Theriogenol., 33: 354-359.

Younis, A. I.; Brackett, B.G. and Fayer - Hosken, R. A. (1989): Influence of serum and hormones on bovine oocytes maturation and fertilization in vitro. Gamete Res., 23:189201.

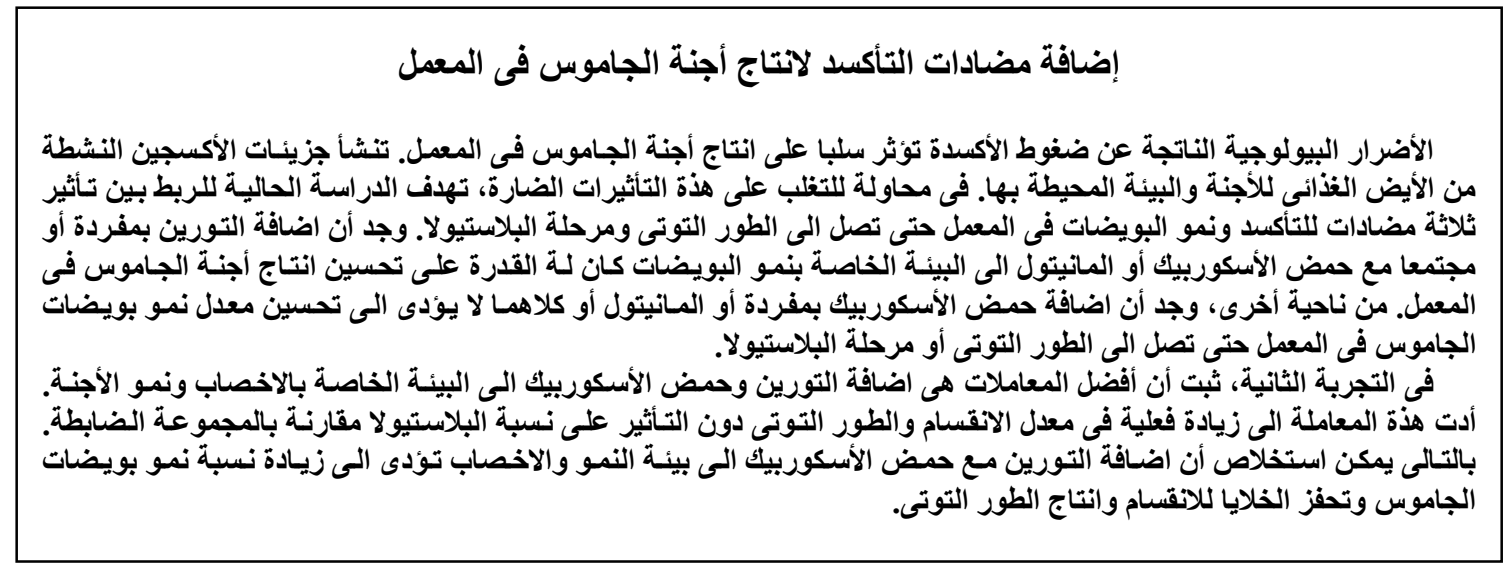

